\title{
Skin matters! The role of keratinocytes in nociception: a rational argument for the development of topical analgesics
}

This article was published in the following Dove Press journal: Journal of Pain Research

16 December 2016

Number of times this article has been viewed

\author{
Jan M Keppel Hesselink' \\ David J Kopsky² \\ Arun K Bhaskar ${ }^{3}$ \\ 'Institute for Neuropathic Pain, Bosch \\ en Duin, the Netherlands; ' Institute \\ for Neuropathic Pain, Vespuccistraat \\ 64-III, Amsterdam, the Netherlands; \\ ${ }^{3}$ Pain management Centre, Charing \\ Cross Hospital Imperial Healthcare \\ NHS Trust, London, United Kingdom
}

Correspondence: David J Kopsky Institute for Neuropathic Pain, Vespuccistraat 64-III, 1056 SN Amsterdam, the Netherlands Tel +3I 62867 1847

Email info@neuropathie.nu

\begin{abstract}
Treatment of neuropathic pain using topical formulations is still in its infancy. Only few topical analgesic formulations have become available for clinical use, and among these, analgesic creams are still rare. This is unfortunate because analgesic creams offer a number of advantages over patches, such as convenience, ease of adapting the frequency of application, and dose, and "rubbing cream where it hurts" involves the patient much more in the therapeutic process compared to patches and other localized treatment modalities. Although the literature supporting the efficacy and safety of analgesic creams (mostly compounded) is growing since the last decade, most pain physicians have not yet noticed and appreciated the therapeutic potential and clinical value of these creams. This is most probably due to a prejudice that topical application should need to act transdermally, more or less as a slow-release formulation, such as in patches delivering opioids. We will discuss this prejudice and show that there are multiple important targets in the skin to be reached by topical analgesic or anti-inflammatory compounds, and that the keratinocyte is one of those targets. By specifically targeting the keratinocyte, analgesia seems possible, effective, and safe, and thus topical analgesic creams may hold promise as a novel treatment modality for neuropathic pain.
\end{abstract}

Keywords: topical, keratinocyte, transdermal delivery, analgesics, neuropathic pain, peripheral sensitization

\section{Introduction}

Topical preparations including analgesics are popular among people and a wide variety of them are used as over-the-counter products. However, there is a paucity of topical analgesic compounds in medical practice. One of the reasons is that peripheral mechanisms in chronic pain have not enjoyed the same degree of attention as central mechanisms. Peripheral mechanisms have long been discovered and described in experimental biology of the skin and peripheral nerves, but this has not been translated into mainstream clinical practice. The objective of this article is to elucidate that peripheral mechanisms are highly relevant for the development of topical treatments for neuropathic pain. Furthermore, the authors aim to bring forth some building blocks for creating a solid foundation for the development of topical analgesia based on varying pharmacological mechanisms of action.

Since more than a decade, there has been a growing interest in topical analgesics, and they are currently discussed as a mainstream option for treating different classes of pain. ${ }^{1-5}$ Such formulations are said to be effective, without troublesome local or systemic side effects, and various formulations such as patches, creams, and gels 
have become available for the prescribing physician. Most of these formulations deliver drugs systemically to act as transdermal delivery systems, whereas lidocaine patches and capsaicin cream and patches mainly act locally without causing any direct systemic effect. Still a significant cohort of pain physicians harbor the belief that topical analgesics need to penetrate transdermally to build up serum levels of the active drug to be efficacious. This is because they feel peripheral mechanisms supporting chronic pain are either absent or not proven to be conclusive.

Such a view has been a road block for the development of novel compounds that act locally with a topical exertion of their action. Surprisingly, some active compounds in topical analgesics have a multitude of effects on different cells in the skin, which all have broad biological functions in nociception and immunity, supporting the rationale for the treatment of neuropathic pain via the skin. ${ }^{6}$ In order to create a new understanding for the putative role of topical analgesia in a stepwise manner, five argumentative elements need to be outlined before we explore all research findings supporting our thesis.

\section{Five elements supporting the use of topical analgesia}

The line of thinking we explore in this article is as follows:

1. The skin is rich in structures cross talking to each other, contributing to peripheral sensitization, and keratinocytes are hitherto a neglected factor and a potential target.

2. In many states of peripheral neuropathy, mild inflammation contributes to the pathogenesis of pain via activation of nociceptors and related skin structures.

3. Peripheral sensitization is a contributing factor for central sensitization and continuous pathogenetic impulses from the periphery might further consolidate and aggravate central sensitization via kindling and potentiation phenomena.

4. Selecting peripheral targets in the epidermis, such as keratinocytes, and inhibiting mild peripheral inflammatory cascades will decrease peripheral sensitization loops.

5. Compounding specific active pharmaceutical ingredients in a topical cream base, without the necessity to deliver the compounds transdermally, have the potential to add to our pharmacological armamentarium in the treatment of neuropathic pain.

We will discuss research findings supporting each of these elements by discussing the biological roles of the 1) keratinocyte related to peripheral sensitization and low-grade peripheral inflammation, 2) network of interplay between keratinocytes, nociceptors, and other nonneuronal cells and their autacoids and neurotransmitters, and 3) various neuronal cell-related and immune-related receptors on the keratinocytes. Based on this structure of argumentation, the authors follow by postulating that transdermal penetration of the active compound may not be required for analgesic activity, because many targets for these analgesics are to be found in the various components of the epidermis. Therefore, skin matters in the treatment of neuropathic pain. ${ }^{7}$

\section{Focus on the keratinocyte}

Generations of medical students and doctors have been taught that the keratinocyte is nothing more than a building block of the skin and accounts for the majority of the cells in the dermis. This is epitomized in a leading textbook on histology from the early part of last century in which the characteristics of the stratum corneum were described, without even mentioning the keratinocyte. ${ }^{8}$ Researchers over the past 30 years have identified that the keratinocytes are not solely programmed to synthesize keratin and subsequently to differentiate terminally into the protective stratum corneum, but also have specialized biological functions. ${ }^{9}$ Keratinocytes are in close functional contact with the sensory afferent nerves, and stimulation of keratinocytes alone is sufficient to induce nociception-related neurophysiological responses. ${ }^{10,11}$ This has also been explored in a different model and activation of keratinocytes expressing channel rhodopsin via blue light can produce action potentials. ${ }^{12}$ Keratinocytes express a number of receptors and synthesize neuropeptides, neurotransmitters, and autacoids ${ }^{13}$ and are also involved in localized inflammatory processes. It is to be acknowledged that these cells may have a key role in the pathogenesis of neuropathic pain. ${ }^{14,15}$ Studies carried out by a specific experimental model for delivering thermal and mechanical stimuli without simultaneously affecting both the keratinocytes and the underlying nerve fibers demonstrated that in response to noxious stimuli, the keratinocyte on its own accord can release several compounds, such as calcitonin gene-related peptide (CGRP), adenosine triphosphate (ATP), acetylcholine, glutamate, various growth factors, cytokines, chemokines, and many other autacoids that play a role in neural and immune mechanisms. ${ }^{16}$ Furthermore, there are a number of findings pointing out the role of low-grade peripheral neurogenic inflammation in neuropathic pain, and such inflammation could also contribute to chronic keratinocyte stimulation and peripheral sensitization. 


\section{Low-grade peripheral neurogenic inflammation}

The concept of low-grade inflammation in the pathogenesis of many chronic disorders is currently widely accepted. We now have a better understanding of the devastating role of chronic low-grade inflammation in disorders varying from obesity and diabetes mellitus to even cardiovascular conditions like atherosclerosis. However, better understanding and appreciation of the role of chronic low-grade neurogenic inflammation in various neuropathies are still lacking. This is illustrated in examples of axonal neuropathies in diabetes, sarcoidosis-associated neuropathy, and other small fiber neuropathies, as well as post-infectious neuropathies as seen in Borreliosis, Epstein-Barr virus, hepatitis C, leprosy, HIV, and post-herpetic neuralgia (PHN). ${ }^{17}$ Such low-grade, secondary inflammation has also been identified in Charcot-Marie-Tooth type 1 neuropathies as a disease amplifier and is proposed as a new target for therapy. ${ }^{18}$

All these abovementioned cases of low-grade inflammatory processes may lead to peripheral nerve damage and consequently trigger enhanced transmitter release within the spinal cord and subsequently lead to central sensitization. ${ }^{19}$ Thus, increased peripheral input through primary afferents and peripheral sensitization are clearly involved in contributing toward central sensitization and the maintenance of neuropathic pain, and most probably also in the chronification of acute pain as seen in post-surgical pain syndromes..$^{20}$ The fact that in some cases topically administered analgesic cream leads to pain reduction in central neuropathic pain states might hint on a more neuroplastic relationship between peripheral and central sensitization as envisaged by several authors. ${ }^{21,22}$ After peripheral nerve injury, various immunocompetent cells as well as fibroblasts are recruited to the injured site and interact with resident cells such as mast cells, keratinocytes, and dendritic cells. ${ }^{23}$ All these lead to the, often described, release of a cascade of inflammatory mediators, resulting in disruption of sensory processing, and induce a cycle of local chronic neurogenic inflammation and subsequently lead to a chronic pain state. Certain sodium channels, such as the $\mathrm{Na}_{\mathrm{v}} 1.8$ channel, are present in nociceptive primary afferent neurons, $\mathrm{A}-\boldsymbol{\delta}$ and $\mathrm{C}$ fibers, and participate in inflammatory hyperalgesia. These channels are instrumental in the maintenance of persistent hypernociception in chronic inflammatory states. ${ }^{24}$ The functional interaction between various intracellular second messengers and the $\mathrm{Na}_{\mathrm{v}} 1.8$ channel in primary sensory neurons has been demonstrated to be an important mechanism for the maintenance of the inflammatory persistent hypernociception. ${ }^{25}$
Pro-inflammatory cytokines can further induce the expression of nociceptive relevant receptors, such as the $\alpha$-1a-adrenoceptor subtype, on a number of cells in the injured tissue and on keratinocytes. ${ }^{26}$ These receptors are also expressed on nerve fibers distributed in the skin. ${ }^{27}$ Noradrenaline itself may act on these upregulated alpha1aadrenoceptors leading to further production of the proinflammatory cytokines, such as interleukin-6 (IL-6) and pain. ${ }^{28}$ In addition, peripheral nerve injury provokes upregulation of $\alpha 1$-adrenoceptors not only on surviving nociceptive afferents but also on keratinocytes in the skin. ${ }^{29}$ This forms the rationale for the efficacy of the $\alpha-1$ a antagonist prazosin in a topical cream preparation, which seemed to attenuate sensitivity to tactile stimuli in patients with complex regional pain syndrome (CRPS). ${ }^{30}$

Studies on CRPS reveal that the keratinocyte plays a role in the initiation of central sensitization; the fact that a peripheral applied topical cream can attenuate symptoms of CRPS supports our thesis, described under the points 1 to 5 in "Five elements supporting the use of topical analgesia" section. ${ }^{31}$ In a CRPS model, upregulated IL-1 $\beta$ mRNA and protein expression in hind paw skin keratinocytes was observed; while IL-1 $\beta$ could induce mechanical allodynia and stimulate keratinocyte NGF expression in the skin, NGF could lead to nociceptive sensitization. ${ }^{32} \mathrm{~A}$ comparable role for the keratinocyte in neuropathic pain has been documented via the analysis of punch biopsies in herpes zoster patients with immunofluorescent staining for TRPV1 in the epidermal keratinocytes. TRPV1 mRNA and protein levels were significantly higher in the affected epidermis than in control epidermis and were correlated with the degree of pain. ${ }^{33}$

\section{Skin matters: the network of keratinocytes, non-neuronal cells, and nerve endings}

Keratinocytes are the most abundant cells in the skin, but the keratinocyte is not the only area of interest in relation to nociception and peripheral sensitization in the skin. There is an intimate interplay between non-neuronal cells such as keratinocytes and various dermal immunocompetent cells, the dendritic cells and mast cells, as well as with the free nerve endings in the skin. Each of these components is able to cross talk with any other component, and a network of interactive factors brings these key players together in the process of nociception and peripheral sensitization.

Keratinocytes contribute to the initial transduction process through regulated release of many neuroactive 
substances. ${ }^{34,35}$ In the past, it has already been pointed out that non-neuronal cells such as the mast cells cross talk with nerve endings, and this was the basis for the efficacy of the autacoid palmitoylethanolamide (PEA) in various mast cellrelated disorders as well as in neuropathic pain. ${ }^{36-38}$ Nociceptors terminate in the periphery as free nerve endings and can directly be in contact with injured tissue; therefore, any cell in the epidermis can serve as a potential sensory receptor for injury. ${ }^{39}$ The close apposition of keratinocytes with such sensory afferents was already identified as early as in $1995 .^{40}$ The interplay between keratinocytes and the primary nerve endings takes place through the entire epidermis on multiple levels, as different neuronal subpopulations terminate in different layers of the epidermis, giving rise to spatially segregated epidermal innervations.

Pathological stimulation of keratinocytes leads to central sensitization. In a keratinocyte stimulation paradigm, TRPV1 can be activated by 4-hydroxy-tamoxifen in in vitro keratinocyte cultures as well as in in vivo models. The latter was via the topical application on the glabrous skin of the hind paw of mice. It has been observed that the stimulation of keratinocyte alone is sufficient to induce strong expression of the neuronal activation marker c-fos, in the dorsal horn of the spinal cord, and evoke pain behavior. ${ }^{10}$ Other findings also support this line of thought. Overexpression of neurotrophins in the keratinocyte leads to neurochemical and neurophysiological changes in sensory neurons, and these skin-derived factors are also important in the development of sensory afferents during the embryonic development. ${ }^{41}$

\section{Keratinocytes: receptor-dense cells}

The following discussion on recent findings related to a number of receptors on the keratinocyte would bring a more robust argument into the understanding and development of topical analgesics. Various sensory receptors and inflammatory markers are expressed on keratinocytes as well as on unmyelinated nerve fibers. These receptors play a role in nociception and include both neuronal-related receptors as well as immune-related receptors: $\alpha 1$-adrenoceptors; voltage-gated sodium channels $\mathrm{Na}_{\mathrm{v}} 1.1, \mathrm{Na}_{\mathrm{v}} 1.2, \mathrm{Na}_{\mathrm{v}} 1.5, \mathrm{Na}_{\mathrm{v}} 1.6$, $\mathrm{Na}_{\mathrm{v}} 1.7$, and $\mathrm{Na}_{\mathrm{v}} 1.8$; temperature-sensitive transient receptor potential ion channels (thermoTRPs) such as the TRPV1-4, substance $\mathrm{P}$ (SP), and neurokinin A; endothelin receptors such as endothelin-1 (ET1) receptors and MrgX3 and MrgX4 receptors; Toll-like receptors; ecto-5' -nucleotidase (NT5E); inflammatory markers such as NALP1 and caspase-1; and interleukin receptors such as IL-1 $\beta$ and IL-31, to mention a few. This article is not aimed at extensively discussing all these receptors but will focus on a few putative key neuronal receptors on the keratinocyte ${ }^{42}$ and their role in nociception.

\section{Neuronal-related receptors on the keratinocyte}

ThermoTRPs, such as TRPV1-4 receptors, as well as the TRPA1 channels are overexpressed in epidermal keratinocytes. ${ }^{43-48}$ It seems quite relevant that such receptors in patients suffering from distal small nerve fiber neuropathy and diabetic neuropathy are moderately to strongly expressed on keratinocytes. ${ }^{49}$ Such receptors are also hypothesized to play a role in "people with sensitive skin" and in nociception and are hypothesized as potential new targets for the treatment of pain. ${ }^{50,51}$ Endogenous ligands for such receptors, such as farnesyl pyrophosphate, an endogenous TRPV3 activator, can induce nociception. ${ }^{52}$ Furthermore, the intracellular pathway triggered by TRPV3 activation is believed to be the calcium- and cyclooxygenase-1 (COX1)-dependent release of prostaglandin $\mathrm{E}_{2}\left(\mathrm{PGE}_{2}\right) .{ }^{53}$ TRPV3 was found to be significantly increased in keratinocytes from pruritic burn scars compared to keratinocytes from non-pruritic burn scars, and it has been noted that itch and pain have many common signaling pathways. ${ }^{54}$ Thermal pain sensitivity can also be modulated by prostaglandin signaling downstream of keratinocyte TRPV3 receptor. ${ }^{53}$ Furthermore, $\mathrm{PGE}_{2}$ is an autacoid by which keratinocyte TRPV3 channels can communicate with cutaneous sensory nerve endings. This interplay between $\mathrm{PGE}_{2}$, sensory transduction, and TRP channels is consistent with the established role of $\mathrm{PGE}_{2}$ as a nociceptive mediator. ${ }^{55}$ It is therefore of great interest to explore the efficacy of novel drug candidates from the autacoid class of resolvins, maresins, and protectins as putative leads in topical creams, as these autacoids can modify inflammatory overactivity due to prostaglandin signaling, as was already pointed out for corneal disorders. ${ }^{56}$ Furthermore, these compounds can specifically inhibit the TRPV3 activation and thus lead to achieving peripheral analgesia. ${ }^{57}$ This would be of more use than combining TRPV antagonists with COX inhibitors, as COX inhibitors may also inhibit the synthesis of important autacoids from the resolvin, maresin, and protectin class, thus inhibiting important pro-resolving pathways.

TRPV4 ion channels can be found both in epidermal keratinocytes and in innervating sensory neurons. TRPV4 has been identified as a critical receptor on the keratinocyte in an excess ultraviolet B model, inducing the keratinocyte in a pain-generator cell. ${ }^{45}$ Both TRPV3 and TRPV4 have found to be significantly increased in keratinocytes in breast pain tissues. ${ }^{58}$ 
Voltage-gated sodium channels, such as $\mathrm{Na}_{\mathrm{v}} 1.1, \mathrm{Na}_{\mathrm{v}} 1.2$, $\mathrm{Na}_{\mathrm{v}} 1.5, \mathrm{Na}_{\mathrm{v}} 1.6, \mathrm{Na}_{\mathrm{v}} 1.7$, and $\mathrm{Na}_{\mathrm{v}} 1.8$, have been localized on keratinocytes in human skin biopsies from patients suffering from CRPS type 1 and PHN..$^{34}$ This led to the suggestion that pathological increases in these sodium channels may contribute to pain via epidermal ATP release. This ATP release leads to an excessive activation of $\mathrm{P} 2 \mathrm{X}$ receptors on primary sensory axons and this triggers peripheral windup. ${ }^{34}$

Increased expression of $\alpha 1$-adrenoceptors has been documented on nociceptive afferents and keratinocytes in a CRPS model and this topic was discussed earlier in this article. ${ }^{59}$ Peptide ET1 receptors are expressed in a variety of other cell types in skin, including keratinocytes, as well as on small-diameter nociceptive neurons. ${ }^{60}$ ET1 receptors in a mouse model for cancer-related pain demonstrated an increase in the number of keratinocytes. ${ }^{61}$ NT5E (CD73) is a membrane-anchored protein which can influence nociception by hydrolyzing AMP to adenosine. NT5E is located on epidermal keratinocytes, various cells of the dermis, and on nociceptive axon terminals in the epidermis. ${ }^{62}$ Neuropeptides such as SP and CGRP induce nociceptive sensitization by enhancing IL- $1 \beta$ production in keratinocytes. This upregulation of IL- $1 \beta$ is suggested to be induced by a NALP1 inflammasome-dependent pathway. ${ }^{63}$ The same neuropeptides cause a further upregulation of neuropeptide receptor expression in keratinocytes and lead to an increase in the secretion of SP and CGRP by keratinocyte, suggesting an autacoid amplification of neuropeptide signaling. Such amplification leads to enhanced IL- 6 and tumor necrosis factor alpha (TNF- $\alpha$ ) secretion in keratinocytes. ${ }^{64} \mathrm{CGRP}$ expression in epidermal keratinocytes is especially high in the skin of patients suffering from PHN and CRPS type 1, and in an animal model of AIDS and in a sciatic nerve chronic constriction model. ${ }^{65}$

\section{Keratinocytes and immune-related receptors and markers}

In the closing decade of the last century, it was already hypothesized that skin keratinocytes that express NGF after loss of contact with the axon, as in painful diabetic neuropathy, still produce substantial quantities of NGF. Subsequently, sprouting nerve fibers in the skin are exposed to a relative excess of NGF and are more susceptible to NGF, resulting in hyperalgesia ${ }^{66}$ It was the Nobel laureate Rita Levi-Montalcini who in the same period pointed out that cells producing NGF in the skin, such as the mast cells, are potential targets for topical modulation with autacoids, and she proved her hypothesis using the autaocoid PEA, a compound currently available as a food supplement as well as a $1 \%$ topical cream. ${ }^{67}$
Keratinocyte activation and proliferation is also hypothesized to be a factor contributing to the pathogenesis of CRPS, as demonstrated in a distal tibia fracture model. Keratinocyte activation to chronic keratinocyte proliferation and a strong upregulation of IL-1 $\beta$, IL- 6 , and TNF- $\alpha$ mRNA and protein levels in skin, as well as a significant upregulation of NGF- $\beta$ in keratinocytes. ${ }^{68}$ Inflammatory markers such as NALP1, caspase-1, and IL-1 $\beta$ are co-expressed in keratinocytes, and the number of NALP1, caspase-1, and IL-1 $\beta$ positive cells also rise dramatically after 4 weeks in such a model ${ }^{69}$ CGRP is expressed by keratinocytes and is increased in painful skin sites from humans with PHN and CRPS type 1. In animal models of inflammatory and nerve injury, CGRP-induced painrelated CGRP receptor components such as CRLR, RAMP1, and RCP have been found to be expressed by keratinocytes. CGRP promotes several functional changes in keratinocytes, including proliferation and cytokine production. ${ }^{65}$ Moreover, it was observed that increase in keratinocyte CGRP immunolabeling does not even require a local inflammatory cascade. ${ }^{65}$

The keratinocytes, however, can also play a role in anti-nociception. CB2 activation by cannabinoid and noncannabinoid cannabis compounds, such as $\beta$-caryophyllene and tetracyclic triterpene euphol, leads to the local release of analgesic compounds such as the endogenous opioid $\beta$-endorphin from keratinocytes. ${ }^{70,71}$ Furthermore, various anti-inflammatory autacoids from the families of $\mathrm{N}$-acylethanolamines, resolvins, protectins, and maresins may contribute to restoring homeostasis and anti-nociceptive activity.

\section{Some putative therapeutic inroads for topical analgesia}

Based on the evidence discussed earlier, topical treatment of neuropathic pain may bring on meaningful analgesia through influencing local compartments of the skin, such as the keratinocyte. Topical treatments can be used either as monotherapy or as part of a multimodal pain management program, and both analgesic and anti-inflammatory compounds could be used or combined in such a topical preparation. The proof of concept has already been presented for a number of topically administered analgesic compounds. ${ }^{4,5,72,73}$ Sadly enough, dose-finding trials are sometimes skipped, leading to negative trials due to insufficient concentration of the topical analgesics or a suboptimal selected cream base. ${ }^{74}$ Much more development work is required in this field.

The emergence of new insight in the therapeutic role of autacoids in restoring neuro-immunological homeostasis also provides a novel option, and such autacoids can be combined in topical creams. The value of PEA in such a preparation, that is, in the form of a cream, is currently being explored. ${ }^{75}$ 
Physicochemical as well as pharmacological properties of the drugs have to be taken into consideration while developing a topical preparation. Lipophilic compounds, for instance, will penetrate more easily into the skin and its target compartments when compounded in specific carriers as compared to hydrophilic drugs. Hydrophilic drugs need more elaborate pharmaceutical compositions, but modern techniques using liposomes are quite suitable for delivering such compounds to the various targets in the skin.

In the Netherlands, we cooperate with a compounding pharmacist who provides prescription analgesic creams, and most health insurance plans cover the expenses. We have thus build up considerable experience in testing and developing a variety of topical creams and selected a specific base, which is able to incorporate effectively both lipophilic as well as hydrophilic compounds (having a molecular weight less than $500 \mathrm{Da}$ ). This enables the successful mixing of the various components without any pharmacological and pharmaceutical complications. The clinical advantage of such a preparation might be that neuropathic pain could be managed by prescribing compounded creams containing one or more drugs such as amitriptyline, ketamine, clonidine, baclofen, and the autacoid PEA. Early observations seem to indicate that there might be a synergistic effect in therapeutic benefit. ${ }^{5,76-83}$,

\section{Conclusion}

Targeting the keratinocyte can be one of the novel breakthroughs in treating neuropathic pain via topical mechanisms in the skin, as outlined in this article. Both anti-inflammatory and analgesic compounds can serve as pharmacological tools in topical formulations to target and influence the keratinocyte and related tissue components, including free nerve endings. The keratinocyte offers a plethora of molecular targets, from alpha 1 receptors to receptors for autacoids, such as PEA, resolvins, and other lipid mediators. The authors postulate that topical formulations containing these compounds may have a role to contribute significantly to the pharmacological armamentaria of the physicians in the treatment of difficultto-treat disorders such as neuropathic pain and CRPS.

\section{Disclosure}

The authors report no conflicts of interest in this work.

\section{References}

1. Argoff CE. Targeted peripheral analgesics therapy for neuropathic pain. Curr Pain Headache Rep. 2004;8(3):199204.

2. de Leon-Casasola OA. Multimodal approaches to the management of neuropathic pain: the role of topical analgesia. J Pain Symptom Manage. 2007;33(3):356-364.
3. Sawynok J. Topical analgesics for neuropathic pain in the elderly: current and future prospects. Drugs Aging. 2014;31(12):853-862.

4. Kopsky DJ, Keppel Hesselink JM, Bhaskar A, Hariton G, Romanenko V, Casale R. Analgesic effects of topical ketamine. Minerva Anestesiol. 2015;81(4):440-449.

5. Kopsky DJ, Hesselink JM. High doses of topical amitriptyline in neuropathic pain: two cases and literature review. Pain Pract. 2012;12(2): 148-153.

6. Irving G. Targeting the skin for treating peripheral neuropathic pain (industry symposium sponsored by Astellas). Eur J Pain Suppl. 2010;4(S1):19.

7. Shipton EA. Skin matters: identifying pain mechanisms and predicting treatment outcomes. Neurol Res Int. 2013;2013:329364.

8. Lewis FT, Stoehr PA. Textbook of Histology. Philadelphia: Blakiston's Son \& Co.; 1913.

9. Choi KL, Sauder DN. The role of Langerhans cells and keratinocytes in epidermal immunity. J Leukoc Biol. 1986;39(3):343-358.

10. Pang Z, Sakamoto T, Tiwari V, et al. Selective keratinocyte stimulation is sufficient to evoke nociception in mice. Pain. 2015;156(4):656-665.

11. Radtke C, Vogt PM, Devor M, Kocsis JD. Keratinocytes acting on injured afferents induce extreme neuronal hyperexcitability and chronic pain. Pain. 2010;148(1):94-102.

12. Baumbauer KM, DeBerry JJ, Adelman PC, et al. Keratinocytes can modulate and directly initiate nociceptive responses. Elife. 2015;2(4):09674.

13. Sloniecka M, Le Roux S, Boman P, Bystrom B, Zhou Q, Danielson P. Expression profiles of neuropeptides, neurotransmitters, and their receptors in human keratocytes in vitro and in situ. PLoS One. 2015; 10(7):e0134157.

14. Cunha TM, Verri WA, Jr, Silva JS, Poole S, Cunha FQ, Ferreira SH. A cascade of cytokines mediates mechanical inflammatory hypernociception in mice. Proc Natl Acad Sci U S A. 2005;102(5):1755-1760.

15. Manjavachi MN, Costa R, Quintao NL, Calixto JB. The role of keratinocyte-derived chemokine (KC) on hyperalgesia caused by peripheral nerve injury in mice. Neuropharmacology. 2014;79:17-27.

16. Ritter-Jones M, Najjar S, Albers KM. Keratinocytes as modulators of sensory afferent firing. Pain. 2016;157(4):786-787.

17. Cashman CR, Hoke A. Mechanisms of distal axonal degeneration in peripheral neuropathies. Neurosci Lett. 2015;596:33-50.

18. Klein D, Patzko A, Schreiber D, et al. Targeting the colony stimulating factor 1 receptor alleviates two forms of Charcot-Marie-Tooth disease in mice. Brain. 2015;138(Pt 11):3193-3205.

19. Baron R, Hans G, Dickenson AH. Peripheral input and its importance for central sensitization. Ann Neurol. 2013;74(5):630-636.

20. Miranda J, Lamana SM, Dias EV, Athie M, Parada CA, Tambeli CH. Effect of pain chronification and chronic pain on an endogenous pain modulation circuit in rats. Neuroscience. 2015;286:37-44.

21. Kopsky DJ, Liebregts R, Keppel Hesselink JM. Central neuropathic pain in a patient with multiple sclerosis treated successfully with topical amitriptyline. Case Rep Med. 2012;2012:471835.

22. Kopsky DJ, Amelink GJ, Keppel Hesselink JM. Intractable neuropathic pain in spinal intramedullary cavernoma treated successfully with a novel combination cream. Pain Med. 2012;13(5):729-730.

23. Reinke JM, Sorg H. Wound repair and regeneration. Eur Surg Res. 2012;49(1):35-43.

24. Villarreal CF, Sachs D, Cunha FQ, Parada CA, Ferreira SH. The role of $\mathrm{Na}(\mathrm{V}) 1.8$ sodium channel in the maintenance of chronic inflammatory hypernociception. Neurosci Lett. 2005;386(2):72-77.

25. Villarreal CF, Sachs D, Funez MI, Parada CA, de Queiroz Cunha F, Ferreira SH. The peripheral pro-nociceptive state induced by repetitive inflammatory stimuli involves continuous activation of protein kinase A and protein kinase $\mathrm{C}$ epsilon and its $\mathrm{Na}(\mathrm{V}) 1.8$ sodium channel functional regulation in the primary sensory neuron. Biochem Pharmacol. 2009;77(5):867-877.

26. Drummond PD, Dawson LF, Finch PM, Drummond ES, Wood FM, Fear MW. Up-regulation of cutaneous alpha1-adrenoceptors after a burn. Burns. 2015;41(6):1227-1234.

27. Dawson LF, Phillips JK, Finch PM, Inglis JJ, Drummond PD. Expression of alpha1-adrenoceptors on peripheral nociceptive neurons. Neuroscience. 2011;175:300314. 
28. Drummond PD. Neuronal changes resulting in up-regulation of alpha-1 adrenoceptors after peripheral nerve injury. Neural Regen Res. 15 2014;9(14): 13371340.

29. Drummond ES, Dawson LF, Finch PM, Bennett GJ, Drummond PD. Increased expression of cutaneous alpha1-adrenoceptors after chronic constriction injury in rats. J Pain. 2014;15(2):188-196.

30. Drummond ES, Maker G, Birklein F, Finch PM, Drummond PD. Topical prazosin attenuates sensitivity to tactile stimuli in patients with complex regional pain syndrome. Eur J Pain. 2016;20(6):926-935.

31. Li WW, Guo TZ, Shi X, et al. Substance P spinal signaling induces glial activation and nociceptive sensitization after fracture. Neuroscience. 2015;310:73-90

32. Li WW, Sabsovich I, Guo TZ, Zhao R, Kingery WS, Clark JD. The role of enhanced cutaneous IL-1beta signaling in a rat tibia fracture model of complex regional pain syndrome. Pain. 2009;144(3):303-313.

33. Han SB, Kim H, Cho SH, Lee JD, Chung JH, Kim HS. Transient receptor potential vanilloid-1 in epidermal keratinocytes may contribute to acute pain in herpes zoster. Acta Derm Venereol. 2016;96(3):319-322.

34. Zhao P, Barr TP, Hou Q, et al. Voltage-gated sodium channel expression in rat and human epidermal keratinocytes: evidence for a role in pain. Pain. 2008;139(1):90-105.

35. Dussor G, Koerber HR, Oaklander AL, Rice FL, Molliver DC. Nucleotide signaling and cutaneous mechanisms of pain transduction. Brain Res Rev. 2009;60(1):2435.

36. Keppel Hesselink JM. The terms 'autacoid', 'hormone' and 'chalone' and how they have shifted with time. Auton Autacoid Pharmacol. 2015; 35(4):51-58.

37. Hesselink JM. Evolution in pharmacologic thinking around the natural analgesic palmitoylethanolamide: from nonspecific resistance to PPARalpha agonist and effective nutraceutical. J Pain Res. 2013;6:625-634

38. Keppel Hesselink JM, Kopsky DJ. Palmitoylethanolamide, a neutraceutical, in nerve compression syndromes: efficacy and safety in sciatic pain and carpal tunnel syndrome. J Pain Res. 2015;8:729-734.

39. Cook SP, McCleskey EW. Cell damage excites nociceptors through release of cytosolic ATP. Pain. 2002;95(1-2):41-47.

40. Hilliges M, Wang L, Johansson O. Ultrastructural evidence for nerve fibers within all vital layers of the human epidermis. J Invest Dermatol. 1995; 104(1):134-137.

41. Albers KM, Davis BM. The skin as a neurotrophic organ. Neuroscientist. 2007;13(4):371-382.

42. Southall MD, Li T, Gharibova LS, Pei Y, Nicol GD, Travers JB. Activation of epidermal vanilloid receptor-1 induces release of proinflammatory mediators in human keratinocytes. $J$ Pharmacol Exp Ther 2003;304(1):217-222.

43. Li WH, Lee YM, Kim JY, et al. Transient receptor potential vanilloid-1 mediates heat-shock-induced matrix metalloproteinase-1 expression in human epidermal keratinocytes. J Invest Dermatol. 2007; 127(10):2328-2335.

44. Ma L, Lee BH, Clifton H, Schaefer S, Zheng J. Nicotinic acid is a common regulator of heat-sensing TRPV1-4 ion channels. Sci Rep. 2015;5:8906

45. Chen Y, Fang Q, Wang Z, et al. Transient receptor potential vanilloid 4 ion channel functions as a pruriceptor in epidermal keratinocytes to evoke histaminergic itch. J Biol Chem. 2016;291(19):10252-10262.

46. Jain A, Bronneke S, Kolbe L, Stab F, Wenck H, Neufang G. TRPchannel-specific cutaneous eicosanoid release patterns. Pain. 2011; 152(12):2765-2772.

47. Bang S, Yoo S, Yang TJ, Cho H, Hwang SW. Nociceptive and proinflammatory effects of dimethylallyl pyrophosphate via TRPV4 activation. Br J Pharmacol. 2012;166(4):1433-1443.

48. Inoue K, Koizumi S, Fuziwara S, Denda S, Denda M. Functional vanilloid receptors in cultured normal human epidermal keratinocytes. Biochem Biophys Res Commun. 2002;291(1):124-129.

49. Wilder-Smith EP, Ong WY, Guo Y, Chow AW. Epidermal transient receptor potential vanilloid 1 in idiopathic small nerve fibre disease, diabetic neuropathy and healthy human subjects. Histopathology. 2007;51(5):674-680.
50. Stander S, Schneider SW, Weishaupt C, Luger TA, Misery L. Putative neuronal mechanisms of sensitive skin. Exp Dermatol. 2009;18(5): 417-423.

51. Salat K, Moniczewski A, Librowski T. Transient receptor potential channels - emerging novel drug targets for the treatment of pain. Curr Med Chem. 2013;20(11):14091436.

52. Bang S, Yoo S, Yang TJ, Cho H, Hwang SW. Farnesyl pyrophosphate is a novel pain-producing molecule via specific activation of TRPV3. J Biol Chem. 18 2010;285(25):19362-19371.

53. Huang SM, Lee H, Chung MK, et al. Overexpressed transient receptor potential vanilloid 3 ion channels in skin keratinocytes modulate pain sensitivity via prostaglandin E2. J Neurosci. 2008;28(51):13727-13737.

54. Kim HO, Cho YS, Park SY, et al. Increased activity of TRPV3 in keratinocytes in hypertrophic burn scars with postburn pruritus. Wound Repair Regen. 2016;24(5):841-850.

55. Guevara C, Fernandez AC, Cardenas R, Suarez-Roca H. Reduction of spinal PGE2 concentrations prevents swim stress-induced thermal hyperalgesia. Neurosci Lett. 2015;591:110-114.

56. Keppel Hesselink JM, Chiosi F, Costagliola C. Resolvins and aliamides: lipid autacoids in ophthalmology, what promise do they hold. Drug Des Devel Ther. 2016;10:3133-3141.

57. Bang S, Yoo S, Yang TJ, Cho H, Hwang SW. 17(R)-resolvin D1 specifically inhibits transient receptor potential ion channel vanilloid 3 leading to peripheral antinociception. Br J Pharmacol. 2012;165(3): 683-692.

58. Gopinath P, Wan E, Holdcroft A, et al. Increased capsaicin receptor TRPV1 in skin nerve fibres and related vanilloid receptors TRPV3 and TRPV4 in keratinocytes in human breast pain. BMC Womens Health. 2005;5(1):2.

59. Finch PM, Drummond ES, Dawson LF, Phillips JK, Drummond PD. Up-regulation of cutaneous alpha1-adrenoceptors in complex regional pain syndrome type I. Pain Med. 2014;15(11):1945-1956.

60. Stosser S, Agarwal N, Tappe-Theodor A, Yanagisawa M, Kuner R. Dissecting the functional significance of endothelin A receptors in peripheral nociceptors in vivo via conditional gene deletion. Pain. 2010;148(2): 206-214.

61. Quang PN, Schmidt BL. Peripheral endothelin B receptor agonistinduced antinociception involves endogenous opioids in mice. Pain. 2010;149(2):254-262

62. Sowa NA, Taylor-Blake B, Zylka MJ. Ecto-5'-nucleotidase (CD73) inhibits nociception by hydrolyzing AMP to adenosine in nociceptive circuits. J Neurosci. 2010;30(6):2235-2244.

63. Shi X, Wang L, Li X, Sahbaie P, Kingery WS, Clark JD. Neuropeptides contribute to peripheral nociceptive sensitization by regulating interleukin-1beta production in keratinocytes. Anesth Analg. 2011;113(1): 175-183.

64. Shi X, Wang L, Clark JD, Kingery WS. Keratinocytes express cytokines and nerve growth factor in response to neuropeptide activation of the ERK1/2 and JNK MAPK transcription pathways. Regul Pept. 2013;186:92-103.

65. Hou Q, Barr T, Gee L, et al. Keratinocyte expression of calcitonin generelated peptide beta: implications for neuropathic and inflammatory pain mechanisms. Pain. 2011;152(9):2036-2051.

66. Anand P. Nerve growth factor regulates nociception in human health and disease. Br J Anaesth. 1995;75(2):201-208.

67. Keppel Hesselink JM. Professor Rita Levi-Montalcini on nerve growth factor, mast cells and palmitoylethanolamide, an endogenous antiInflammatory and analgesic compound. J Pain Relief. 2013;2:114.

68. Li WW, Guo TZ, Li XQ, Kingery WS, Clark JD. Fracture induces keratinocyte activation, proliferation, and expression of pro-nociceptive inflammatory mediators. Pain. 2010;151(3):843-852.

69. Li WW, Guo TZ, Liang D, et al. The NALP1 inflammasome controls cytokine production and nociception in a rat fracture model of complex regional pain syndrome. Pain. 2009;147(1-3):277286.

70. Gao F, Zhang LH, Su TF, et al. Signaling mechanism of cannabinoid receptor-2 activation-induced beta-endorphin release. Mol Neurobiol. $2016 ; 53: 3616$ 
71. Katsuyama S, Mizoguchi H, Kuwahata H, et al. Involvement of peripheral cannabinoid and opioid receptors in beta-caryophyllene-induced antinociception. Eur J Pain. 2013;17(5):664675.

72. Finch PM, Knudsen L, Drummond PD. Reduction of allodynia in patients with complex regional pain syndrome: a double-blind placebocontrolled trial of topical ketamine. Pain. 2009;146(1-2):18-25.

73. Somberg JC, Molnar J. Retrospective study on the analgesic activity of a topical (TT-CTAC) cream in patients with diabetic neuropathy and other chronic pain conditions. Am J Ther. 2015;22(3):214-221.

74. Gewandter JS, Mohile SG, Heckler CE, et al. A phase III randomized, placebo-controlled study of topical amitriptyline and ketamine for chemotherapy-induced peripheral neuropathy (CIPN): a University of Rochester CCOP study of 462 cancer survivors. Support Care Cancer. 2014;22(7):1807-1814.

75. Keppel Hesselink JM, Kopsky DJ, Sajben N. New topical treatment of vulvodynia based on the pathogenetic role of cross talk between nociceptors, immunocompetent cells, and epithelial cells. J Pain Res. 2016;9:757-762.

76. Kopsky DJ, Keppel Hesselink JM. A new combination cream for the treatment of severe neuropathic pain. J Pain Symptom Manage. 2010; 39(2):e9-e10.
77. Kopsky DJ, Keppel Hesselink JM. Neuropathic pain as a result of acromegaly, treated with topical baclofen cream. J Pain Symptom Manage. 2013;46(4):e4e5.

78. Keppel Hesselink JM, Kopsky DJ, Sajben NL. Vulvodynia and proctodynia treated with topical baclofen $5 \%$ and palmitoylethanolamide. Arch Gynecol Obstet. 2014;290(2):389-393.

79. Keppel Hesselink JM, Kopsky DJ. Treatment of chronic regional pain syndrome type 1 with palmitoylethanolamide and topical ketamine cream: modulation of nonneuronal cells. J Pain Res. 2013;6: 239-245.

80. Liebregts R, Kopsky DJ, Hesselink JM. Topical amitriptyline in posttraumatic neuropathic pain. J Pain Symptom Manage. 2011;41(4):e6e7.

81. Kopsky DJ, Keppel Hesselink JM, Casale R. Walking with neuropathic pain: paradoxical shift from burden to support. Case Rep Med. 2015;2015:764950.

82. Kopsky DJ, Amelink GJ, Keppel Hesselink JM. Intractable neuropathic pain in spinal intramedullary cavernoma treated successfully with a novel combination cream. Pain Med. 2012;13(5):729-730.

83. Hesselink JM, Kopsky DJ. Intractable neuropathic pain due to ulnar nerve entrapment treated with cannabis and ketamine $10 \%$. J Clin Anesth. 2012;24(1):78-79.
Journal of Pain Research

\section{Publish your work in this journal}

The Journal of Pain Research is an international, peer reviewed, open access, online journal that welcomes laboratory and clinical findings in the fields of pain research and the prevention and management of pain. Original research, reviews, symposium reports, hypothesis formation and commentaries are all considered for publication.

\section{Dovepress}

The manuscript management system is completely online and includes a very quick and fair peer-review system, which is all easy to use. Visit http://www.dovepress.com/testimonials.php to read real quotes from published authors. 